\title{
Keberfungsian Keluarga Bagi Penyesuain Sosial Mahasiswa Baru
}

\author{
Rofika Dewi Maulina, Sofa Amalia \\ Fakultas Psikologi, Universitas Muhammadiyah Malang \\ email:rofikad@gmail.com
}

\begin{abstract}
Abstrak
Penyesuaian sosial sangat dibutuhkan oleh mahasiswa baru saat memasuki perguruan tinggi agar mereka dapat menyesuaikan diri dengan lingkungan baru tempat mereka belajar. Salah satu faktor yang mempengaruhi penyesuaian sosial adalah keberfungsi keluarga. Tujuan penelitian ini adalah untuk mengetahui pengaruh keberfungsian keluarga terhadap penyesuaian sosial pada mahasiswa baru. Penelitian ini menggunakan desain penelitian korelasional dengan teknik sampling yaitu simple random sampling, dengan subjek penelitian adalah mahasiswa baru usia 17 - 21 tahun sebanyak 268 subjek. Instrumen dalam penelitian ini menggunakan skala The McMaster Family Assessment Device (FAD) dan sub skala social adjustment dari The Student Adaptation to College Questionnaire (SACQ-SA). Analisa data menggunakan uji regresi linier sederhana. Hasil penelitian menunjukkan bahwa terdapat pengaruh keberfungsian keluarga terhadap penyesuaian sosial pada mahasiswa baru. Nilai koefisien regresi $(r)$ sebesar 0,301 dengan nilai $p=0,000(<0,05)$. Hal tersebut menunjukkan bahwa semakin tinggi keberfungsian keluarganya maka semakin tinggi pula penyesuaian sosial mahasiswa baru di perguruan tinggi.
\end{abstract}

Artikel INFO

Diterima:01 April 2019

Direvisi :02 Juli 2019

Disetujui: 23 Juli2019

DOI:

http://dx.doi.org/10.24014/ jp.v14i2.6886

Kata Kunci : Keberfungsian Keluarga, Penyesuaian Sosial, Mahasiswa Baru

\section{Family Functioning For New Students Social Adjustment}

\begin{abstract}
Social adjustment is needed by new students when entering college so that they can adjust to the new environment in which they are studying. One of the factors that can influence social adjustment is family functioning. The aim of this study was to determine the effect of family functioning on social adjustment in new collage students. This study used a correlation research design with simple random sampling as sampling technique, and 268 subjects of new collage student aged 17-21 years. The instrument in this study used the scale of The McMaster Family Assessment Device (FAD) and social adjustment subscale of The Student Adaptation to College Questionnaire (SACQ-SA). Data analysis using simple linear regression test. The outcome showed that there was an influence of family functioning on social adjustment in new collage students. The regression coefficient ( $r$ ) is 0.301 with a value of $p=0,000<0.05$. It shows that the higher the family functioning, the higher the social adjustment of new students in college.
\end{abstract}

Keywords: Family Functioning, Social Adjustment, New Student

\section{Pendahuluan}

Saat memasuki perguruan tinggi mahasiswa dituntut untuk bisa melakukan penyesuaian sosial dengan lingkungan dan situasi yang baru. Penyesuaian sosial mahasiswa di perguruan tinggi mencakup beberapa elemen penting seperti mencoba untuk mengembangkan integrasi sosial 
dengan mahasiswa lain, bersosialisasi dengan mahasiswa lain, mengikuti kegiatan sosial atau komunitas bersama mahasiswa, dosen dan staf perguruan tinggi lainnya (Kaljahi, 2016). Oleh karena itu, mahasiswa baru membutuhkan kesiapan mental dan sosial untuk menghadapi kehidupan baru di perguruan tinggi agar dapat hidup dan bergaul secara wajar dengan lingkungannya, serta merasa puas terhadap diri dan lingkungannya (Willis, 2012).

Dari hasil wawancara yang dilakukan kepada beberapa mahasiswa baru pada tanggal 26 November 2018, secara umum mahasiswa baru memiliki permasalahan dalam memulai hubungan-hubungan dengan teman-teman baru di perkuliahan, perbedaan latar belakang sosial-budaya dengan teman, organisasi dan lingkungan tempat tinggalnya yang baru, berbedanya sistem pelajaran SMA dan perguruan tinggi dan permasalahan karena berpisah dari keluarga. Beberapa penelitian menemukan bahwa mahasiswa baru mengalami permasalahan penyesuaian sosial di lingkungan perguruan tinggi yang berhubungan dengan budaya, agama dan pemisahan dari keluarga dan teman, bahasa, keuangan, dukungan sosial yang buruk dan mengalami kesulitan dalam beradaptasi dengan peran baru mereka (Estiane, 2015; Mudhovozi, 2012; Maundeni, Malinga, Kgwatalala, \& Kasule, 2010).

Penyesuaian sosial diartikan sebagai kemampuan individu untuk menyesuaikan diri dengan lingkungan sosialnya tanpa menimbulkan konflik bagi dirinya maupun lingkungannya. Penyesuaian sosial juga merupakan proses mental dan tingkah laku yang mendorong seseorang untuk menyesuaikan diri dengan keinginan yang berasal dari dalam dirinya sehingga dapat diterima oleh lingkungannya (Schneiders, 2010). Penyesuaian sosial di perguruan tinggi adalah kemampuan seseorang untuk mengatasikebutuhan masyarakat dantuntutan interpersonal dari kehidupan pendidikan mereka dengan mengambil bagian dalam kerja kelompok, membentuk persahabatan dengan mahasiswa lain dan melibatkan diri dalam program ekstra kurikuler dari perguruan tinggi mereka (Baker \& Siryk, 1986).

Pada masa remaja penyesuaian sosial penting untuk dilakukan dan merupakan salah satu tugas perkembangan yang paling sulit karena menuntut kemampuan remaja untuk mengikuti perubahan di dalam lingkungan (Hurlock, 2003). Jadi apabila remaja tidak dapat mengikuti perubahan sosial dalam bergaul dengan lingkungan sekitar maka akan timbul masalah dan kesulitan dalam bersikap dan berinteraksi. Hal tersebut sesuai dengan penelitian Roberson, Fish, Olmstead, \& Fincham (2015) yang menyatakan bahwa mahasiswayang bersikap menolakrealitas dan lingkungan sosial akan merasa terasing dari lingkungannya sehingga ia tidak mengalami kebahagiaan saat berinteraksi dengan temantemannya, kakak tingkat ataupun adik tingkat, dosen, dan staf kampus lainnya. Penyesuaian sosial penting untuk dikembangkan pada mahasiswa karena kesuksesan penyesuaian diri dalam lingkungan sosial dan budaya di kampus juga dapat mendukung kesuksesan prestasi akademik (Yusoff \& Chelliah, 2010).

Terdapat beberapa faktor yang dapat mempengaruhi penyesuaian sosial seperti peran keluarga, bimbingan orang tua dan pola perilaku sosial yang dikembangkan. SmojverAzic, Zivcic-Becirevic, \& Jakov (2010) mengatakan bahwa penyesuaian mahasiswa membutuhkan dukungan dari berbagai pihak, salah satunya orang tua. Orang tua perlu membantu anak dalam penyesuaian diri dan sosialnya dengan memberikan dukungan, perhatian, mengawasi perilaku dan keberadaan anak, serta menjadi komunikator yang baik (Santrock, 2007). Rahayu \& Hartati (2015), juga menyebutkan bahwa semakin tinggi dukungan sosial ayah, maka semakin tinggi penyesuaian sosial pada remaja lakilaki.

Penelitian Barbarin \& Jean-Baptiste (2013) menyebutkan adanya komunikasi intensifyang dilakukan dengan dialog bersama orang tua dan anak, penerapan kontrol orang tua terhadap anak dapat mendukung terbentuknya kompetensi sosial pada anak. Kurangnya kehangatan atau pengawasan orang tua dapat memicu munculnya perilaku anti sosial yang mencerminkan rendahnya 
penyesuaian sosial (Rodgers \& Rose, 2002). Selain itu, penelitian Rhoades \& Wood (2014) juga menunjukkan bahwa apa yang individu rasakan dan persepsikan di sekitar keluarga mereka akan mempengaruhi penyesuaian sosialnya karena individu belajar tentang berinteraksi dengan orang lain dari model yang ada di keluarga. Keluarga juga memiliki fungsi untuk menyediakan interaksi antar teman, kerja sama serta tantangan untuk menguji kemampuan individu dan meningkatkan penyesuaian sosialnya (Najam us Sahar \& Muzaffar, 2017). Dengan demikian, untuk mengembangkan penyesuaian sosial mahasiswa diperlukan keberfungsian keluarganya.

Menurut Epstein-Lubow, Beevers, Bishop, dan Miller (2009) keberfungsian keluarga mengacu pada bagaimana seluruh anggota keluarga dapat saling berkomunikasi, melakukan pekerjaan bersama, dan saling membantu dimana hal tersebut memiliki pengaruh bagi kesehatan fisik dan emosi anggota keluarga. Byles, Byrne, Boyle, \& Offord (1988) mengemukakan bahwa ketika keluarga berfungsi dengan baik maka anggota keluarga dapat melakukan penyelesaikan masalah, mendukung satu sama lain, berkomunikasi efektif, dan menanggapi suatu tantangan yang timbul dengan empatik. Keluarga yang berfungsi secara sehat dapat menyebabkan berkembangnya potensi di setiap anggota keluarga mereka karena keberfungsian keluarga memiliki hubungan dengan kesejahteraan psikologis remaja, penyesuaian sosial di sekolah dan perilaku bermasalah remaja (Shek, 2002).

Sesuai dengan teori sistem keluarga yang menyebutkan bahwa keberfungsian keluargamemilikipengaruh padapertumbuhan dan perilaku setiap anggota dan memainkan peran penting dalam kehidupan sosial setiap anggota keluarga (Epstein, Bishop, \& Levin, 1978). Cara berpikir dan perilaku mahasiswa di lingkungan akademiknya dan secara tidak langsung akan mempengaruhi penyesuaian sosial mahasiswa (Al-Ghamdi, B., \& AlNahal, 2014). Dengan begitu dapat dikatakan bahwa keberfungsian keluarga akan sangat mempengaruhi dan berperan penting dalam penyesuaian sosial mahasiswa di perguruan tinggi. Jika fungsi keluarganya tidak dapat berfungsi dengan baik maka akan berdampak pada penyesuaian sosial mahasiswa dan menimbulkan hal-hal negatif seperti tidak tertarik dan ikut berpartisipasi dalam kegiatan di perguruan tinggi, tidak dapat menjalin relasi sosial yang sehat dengan teman di kelas, kakak tingkat maupun adik tingkat, dosen, dan staf lainnya, serta akan mempengaruhi komitmen mahasiswa dengan lembaga dan harapan mahasiswa akan kemungkinan untuk menyelesaikan pendidikan mereka di perguruan tinggi (Schneider \& Ward, 2003; Soledad et al., 2012). Oleh karena itu keberfungsian keluarga sangat dibutuhkan untuk mahasiswa terutama mahasiswa baru, karena dengan berfungsinya fungsi keluarga maka akan membantu penyesuaian sosial mahasiswa baru di perguruan tinggi.

Dari penjabaran di atas dapat disimpulkan bahwa penelitian ini meneliti mengenai pengaruh keberfungsian keluarga terhadap penyesuaian sosial pada mahasiswa baru. Penelitian ini dipilih karena kedua variabel yaitu keberfungsian keluarga dan penyesuaian sosial belum diteliti dalam 5 tahun terakhir. Tujuan dari penelitian ini adalah ingin mengetahui apakah ada pengaruh antara keberfungsian keluarga terhadap penyesuaian sosial pada mahasiswa baru. Hasil dari penelitian pengaruh keberfungsian keluarga terhadap penyesuaian sosial pada mahasiswa baru di perguruan tinggi ini diharapkan dapat memberikan sumbangan ilmu pengetahuan di bidang psikologi. Selain itu, penelitian ini diharapkan juga dapat membantu mahasiswa dalam meningkatkan penyesuaian sosialnya di perguruan tinggi dan juga dapat bermanfaat bagi orang tua, guru atau dosen agar mengetahui bahwa fungsi keluarga memiliki peran penting dalam penyesuaian sosial remaja. Selanjutnya, penelitian ini diharapkan dapat digunakan sebagai salah satu referensi untuk mengembangkan penelitian-penelitian mengenai pengaruh keberfungsian keluarga terhadap penyesuaian sosial remaja di masa yang akan datang. 


\section{Metode}

\section{Subjek}

Sampel pada penelitian ini adalah 268 mahasiswa angkatan 2018 Universitas Muhammadiyah Malang. Pengambilan subjek menggunakan simple random sampling sehingga setiap sampel yang ada di dalam populasi memiliki kesempatan untuk dipilih (Winarsunu, 2017). Data demografis dapat dilihat di Tabel 1.

Tabel 1. Deskripsi Data Demografis Subjek Penelitian

\begin{tabular}{|c|c|c|}
\hline Kategori & $\mathbf{N}$ & $\%$ \\
\hline \multicolumn{3}{|l|}{ Usia } \\
\hline 17 - 18 tahun & 111 & $41,41 \%$ \\
\hline $19-21$ tahun & 155 & $58,59 \%$ \\
\hline \multicolumn{3}{|l|}{ Jenis Kelamin } \\
\hline Laki-Laki & 184 & $69 \%$ \\
\hline Perempuan & 84 & $31 \%$ \\
\hline \multicolumn{3}{|l|}{ Anak ke } \\
\hline Pertama & 101 & $38 \%$ \\
\hline Tengah & 63 & $24 \%$ \\
\hline Terakhir & 87 & $32 \%$ \\
\hline Tunggal & 17 & $6 \%$ \\
\hline \multicolumn{3}{|l|}{ Status Orang tua } \\
\hline Utuh & 228 & $85 \%$ \\
\hline Cerai & 20 & $7 \%$ \\
\hline $\begin{array}{l}\text { Salah satu orang tua } \\
\text { meninggal }\end{array}$ & 20 & $7 \%$ \\
\hline \multicolumn{3}{|l|}{$\begin{array}{l}\text { Tempat Tinggal di } \\
\text { Malang }\end{array}$} \\
\hline Orangtua & 43 & $16 \%$ \\
\hline Saudara & 18 & $7 \%$ \\
\hline $\begin{array}{l}\text { Kos/Kontrakan/ } \\
\text { Asrama }\end{array}$ & 207 & $77 \%$ \\
\hline
\end{tabular}

Pengukuran

Keberfungsian keluarga adalah penilaian mahasiswa baru terhadap perilaku setiap anggota keluarga terkait komunikasi, keterbukaan, kerja sama, membantu dan mendukung, serta penyelesain masalah yang dapat mempengaruhi emosi dan perilaku yang diukur menggunakan modifikasi skala The McMaster Family Assessment Device (FAD). Skala FAD disusun oleh Epstein et al. (1983) dengan 53 aitem dan 7 dimensi yakni: penyelesaian masalah (5 aitem), komunikasi (6 aitem), peran (8 aitem), keterlibatan afektif (7 aitem), respon afek (6 aitem), kontrol perilaku (9 aitem) dan fungsi umum (12 aitem). Alat ukur ini menggunakan skala likert dengan konsep (favorable) untuk pernyataan atau aitem yang mendukung dan konsep (unfavorable) untuk pernyataan atau aitem yang tidak mendukung. Setiap aitem atau pernyataan memiliki empat pilihan jawaban yaitu: Sangat Setuju (SS), Setuju (S), Tidak Setuju (TS), dan Sangat Tidak Setuju (STS). Coefficients alpha variabel adalah sebesar 0,95 . Validitas alat ukur menggunakan validitas dari expert judgement.

Penyesuaian sosial adalah kemampuan mahasiswa baru untuk menyesuaikan diri dengan lingkungan sosial pendidikannya tanpa menimbulkan konflik bagi dirinya maupun lingkungannya dan diukur menggunakan modifikasi sub skala social adjustment dari The Student Adaptation to College Questionnaire (SACQ-SA). Skala ini disusun oleh Baker \& Siryk (1984). Sub skala yang diambil adalah sub skala social adjustment yang terdiri dari 20 aitem dan berdasarkan 4 dimensi yaitu general (7 aitem), other people (7 aitem), nostalgia (3 aitem), dan social environment (3 aitem). Pengukuran skala dinilai menggunakan empat pilihan jawaban yaitu: Sangat Setuju (SS), Setuju (S), Tidak Setuju (TS), dan Sangat Tidak Setuju (STS). Terdapat 3 kategori skor yaitu tinggi dan rendah. Semakin tinggi skor aitem, maka semakin baik penyesuaian sosial di perguruan tinggi. Validitas alat ukur menggunakan validitas dari expert judgement dan coefficients alpha untuk sub skala social adjustment dari The Student Adaptation to College Questionnaire (SACQ-SA) sebesar 0,80. 


\section{Analisis Data}

Penelitian ini akan dilakukan melalui tiga prosedur yaitu: Persiapan dimulai dari peneliti melakukan pendalaman materi melalui kajian teoritik, membuat desain penelitian dan menyiapkan instrumen. Peneliti mengadaptasi instrumen penelitian kedalam bahasa Indonesia menggunakan penerjemah professional lalu melakukan validitas isi atau validitas konten untuk instrument dengan menggunakan expert judgement. Hal tersebut dilakukan untuk melihat sejauh mana konten atau aitem dari variabel sesuai dengan teori dan menggunakan expert rating atau expert judgement sebagai penilai (Hughes, 2018). Untuk melihat reliabilitas, peneliti menggunakan analisis SPSS dengan melihat coefficients alpha atau cronbach's alpha.

Kemudian, peneliti meminta ijin untuk melakukan tryout dan melakukan penelitian (pengambilan data) kepada mahasiswa baru Universitas Muhammadiyah Malang. Try out pertama dilakukan kepada 72 subjek dengan coefficients alpha variabel keberfungsian keluarga sebesar 0,78 dan variabel penyesuaian sosial sebesar 0,69. Try out kedua dilakukan kepada 61 subjek coefficients alpha variabel keberfungsian keluarga sebesar 0,95 dan variabel penyesuaian sosial sebesar 0,80.

Pelaksanaan, pada tahap ini peneliti menyebarkan skala pada mahasiswa baru Universitas Muhammadiyah Malang yang sedang mengikuti kegiatan P2KK (Program Pembentukan Kepribadian dan Kepemimpinan). Terakhir yaitu menganalisa data yang didapatkan dari penyebaran dua skala yaitu skala penyesuaian sosial (sub skala social adjustment dari The Student Adaptation to College Questionnair) dan skala keberfungsian keluarga (The McMaster Family Assessment Device). Data yang telah diperoleh kemudian diinput dan dianalisa menggunakan program IBM SPSS Statistics 25 dengan menggunakan analisis regresi linier sederhana. Sebelum melakukan uji regresi, peneliti melakukan uji normalitas skweness kurtosis dan uji linieritas terlebih dahulu. Hasil uji normalitas menunjukkan data terdistribusi normal. Nilai skewness keberfungsian keluarga adalah -1,70 dan penyesuaian sosial sebesar 0,70 sedangkan nilai kurtosis keberfungsian keluarga adalah $-0,04$ dan penyesuaian sosial sebesar 0,65. Hasil uji linearitas yang dilakukan pada kedua variabel dikatakan linear karena nilai signifikansi keduanya yaitu keberfungsian keluarga dan penyesuaian sosial adalah sebesar 0,557 $(p>0,05)$. Setelah melakukan analisa data maka peneliti mulai menyusun pembahasan, kesimpulan, serta kekurangan maupun kelebihan dari penelitian yang telah dilakukan.

\section{Hasil}

Hasil uji statistik menunjukkan nilai rata-rata dan standar deviasi variabel keberfungsian keluarga dan variabel penyesuaian sosial sebagai berikut:

\section{Tabel 2. Mean dan Standar Deviasi Variabel $(\mathrm{N}=\mathbf{2 6 8})$}

\begin{tabular}{|c|c|c|}
\hline Variabel & Mean & SD \\
\hline $\begin{array}{l}\text { Keberfungsian } \\
\text { Keluarga }\end{array}$ & 159,92 & 13,37 \\
\hline Penyesuaian Sosial & 57,51 & 6,01 \\
\hline
\end{tabular}

Berdasarkan hasil uji regesi disimpulkan bahwaterdapatpengaruh positifkeberfungsian keluarga terhadap penyesuaian sosial yang artinya semakin tinggi keberfungsian keluarga, maka semakin tinggi pula penyesuaian sosialnya dapat diterima $\left(r=0,30 ; R^{2}=0,09 ; p\right.$ $=0,00)$. Dengan demikian hipotesis peneltian diterima.

Hasil uji korelasi antara dimensi keberfungsian keluarga terhadap penyesuaian sosial diperoleh bahwa nilai koefisien korelasi dimensi peran dalam variabel keberfungsian keluarga terhadap penyesuaian sosial lebih besar daripada dimensi lain yaitu sebesar 0,27 . Nilai koefisien korelasi dimensi dimensi dalam keberfungsian keluarga seperti penyelesaian masalah $(0,19)$, komunikasi $(0,19)$, keterlibatan afektif $(0,04)$, respon afek $(0,19)$, kontrol perilaku $(0,22)$ dan fungsi umum $(0,24)$. Data hasil regresi dan korelasi 
dapat dilihat di Tabel 3.

Tabel 3. Uji Korelasi dan Regresi Keberfungsian Keluarga dan Penyesuaian Sosial

\begin{tabular}{lcccc}
\hline \multicolumn{1}{c}{ Variabel } & $\begin{array}{c}\text { Penyesu- } \\
\text { aian } \\
\text { Sosial }\end{array}$ & $\boldsymbol{R}$ & $\boldsymbol{R}^{\mathbf{2}}$ & $\boldsymbol{p}$ \\
\hline $\begin{array}{l}\text { Keberfungsian } \\
\text { Keluarga }\end{array}$ & & 0,30 & 0,09 & 0,00 \\
$\begin{array}{l}\text { Penyelesaian } \\
\text { masalah }\end{array}$ & 0,19 & & & \\
Komunikasi & 0,19 & & \\
Peran & 0,27 \\
$\begin{array}{l}\text { Keterlibatan } \\
\text { Afektif }\end{array}$ & 0,04 \\
Respon Afek & 0,19 \\
Kontrol & 0,22 \\
Perilaku & 0,24 \\
Fungsi Umum & & \\
\hline
\end{tabular}

\section{Pembahasan}

Hasil penelitian ini menunjukkan bahwa terdapat pengaruh keberfungsian keluarga terhadap penyesuaian sosial pada mahasiswa baru. Hal ini sesuai dengan penelitian yang dilakukan oleh Mohammadyfar, Kazemi, \& Matekolaee (2016) pada 250 remaja di Iran di kota Amiriyeh dengan hasil penelitian bahwa fungsi keluarga memiliki peranan yang signifikan pada penyesuaian sosial siswa. Penelitian Parsian, Igoli, \& Sayadi (2017), juga menyebutkan bahwa keberfungsian keluarga dan regulasi diri memiliki pengaruh terhadap penyesuaian sosial.

Penelitian lain yang sejalan dengan hasil penelitian ini menyebutkan bahwa peran orangtua, hubungan antar saudara, dukungan sosial dan emosional keluarga, keterlibatan orangtua, hubungan orangtuaanak, dinamika keluarga, dan kondisi sosial ekonomi, dan keluarga memiliki pengaruh yang sangat penting untuk perkembangan emosi dan sosial anak yang nantinya akan mempengaruhi penyesuaian sosialnya (Ernawati ,2011; Usoroh, Akpan, Amadi, \& Ezenwa 2014; Rahayu \& Hartati, 2015; AlRawwad, 2016; Mistry, Vandewater, Huston,
\& Mcloyd ,2018 dan Julia \& Veni, 2012). Lebih lanjut dalam penelitian Deepshikha \& Bhanot (2011) mengatakan bahwa penerimaan dan kepedulian, tingkat dukungan, bantuan dan komitmen dalam keluarga, sejauh mana aturan yang ditetapkan diikuti dalam keluarga, konflik keluarga dan sejauh mana anggota keluarga bersikap asertif, mandiri serta membuat keputusan sendiri keluarga juga menunjukkan peran penting dalam penyesuaian sosio-emosi pada individu.

Hasil penelitian ini sejalan dengan teori sistem keluarga yang menyebutkan bahwa interaksi semua anggota keluarga dapat membentuk perilaku anggota keluarga (Epstein et al., 1978). Dalam sistem keluarga, fungsi dasar keluarga adalah menyediakan kondisi lingkungan yang sesuai bagi anggota keluarga agar aspek fisik, psikologis, sosial dan mental semua anggota keluarga dapat berkembang (Dai \& Wang, 2015). Selain itu, keluarga juga dapat mempengaruhi pertumbuhan dan perilaku anggota keluarga serta mendorong kemandirian dan kreativitas anggota keluarga yang berperan penting dalam kehidupan sosial setiap anggota keluarga (Epstein et al., 1978). Peneletian Barbarin \& Jean-Baptiste (2013) menyebutkan adanya komunikasi intensif yang dilakukan dengan dialog bersama orang tua dan anak, penerapan kontrol orang tua terhadap anak dapat mendukung terbentuknya kompetensi sosial pada anak. Keluarga juga berfungsi untuk menyediakan interaksi antar teman, kerjasama serta tantangan untuk menguji kemampuan atau kompetensi individu. Peningkatan kompetensi, komunikasi dan koordinasi yang ada dalam keluarga akan membantu individu dalam melakukan penyesuaian sosial (Najam us Sahar \& Muzaffar, 2017).

Hasil penelitian ini sejalan dengan penelitian Shek (1997) yang menyebutkan bahwa keluarga yang berfungsi secara sehat dapat menyebabkan berkembangnya potensi di setiap anggota keluarga sedangkan individu yang keberfungsian keluarganya rendah memiliki lebih banyak masalah kesehatan mental, perilaku bermasalah dan memiliki penyesuaian sosial yang rendah 
pula. Penelitian Nasir, Ahmad, Khairudin, \& Latipun (2010) juga menunjukkan bahwa fungsi keluarga dan harga diri secara signifikan mempengaruhi distorsi kognitif. Peningkatan distorsi kognitif, mencerminkan peningkatan masalah perilaku (Panourgia \& Comeretto, 2017). Seseorang yang melatih penyesuaian dirinya sejak di lingkungan keluarga maka akan mampu menyesuaikan diri di lingkungan akademiknya (Magnuson, Duncan, Lee, \& Metzger, 2016). Selanjutnya cara berpikir dan perilaku mahasiswa di lingkungan akademiknya dan secara tidak langsung akan mempengaruhi penyesuaian sosial mahasiswa (Al-Ghamdi, B., \& Al-Nahal, 2014).

Dimensi peran memiliki hubungan yang paling tinggi terhadap penyesuaian sosial dari ketujuh dimensi keberfungsian keluarga lainnya. Selanjutunya dimensi kontrol perilaku dan fungsi umum juga memiliki hubungan yang paling tinggi setelah dimensi peran terhadap penyesuaian sosial artinya dimensi peran, control perilaku dan fungsi umum memiliki hubungan yang lebih dominan dengan variabel penyesuaian sosial daripada dimensi lainnya. Dimensi peran dalam keberfungsian keluarga memiliki arti bagaimana sebuah keluarga melakukan proses alokasi atau penyebaran tanggung jawab bagi seluruh anggota keluarga dan menyelesaikan tanggung jawab yang diberikan secara penuh dan berkomitmen dalam melaksanakannya sedangkan dimensi kontrol perilaku adalah standar keluarga dalam mengatur perilaku anggota keluarga (Epstein et al., 1983). Hal tersebut sejalan dengan pelitian Sheehan \& larocci (2015) juga menyebutkan bahwa peran dalam keluarga, posisi dalam keluarga dan relasi dengan anggota keluarga lain akan mempengaruhi kebiasaan, sikap, dan pola perilaku individu. Penelitian Ernawati (2011) yang menyebutkan bahwa peran ibu dan ayah memiliki hubungan yang signifikan terhadap penyesuaian sosial anak. Penelitian lain yang sejalan dengan pendapat diatas juga ditemukan oleh Syaripudin \& Djamhoer (2017) yang menyebutkan bahwa kontrol perilaku memiliki hubungan terhadap penyesuaian sosial siswa yang membuat siswa mengikuti peraturan sekolah, mengerjakan tugas-tugas yang diberikan dan mengikuti kegiatankegiatan sekolah.

Selanjutnya, dimensi keterlibatan afektif memilikihubunganyang palingrendahterhadap penyesuaian sosial diantara dimensi lainnya dalam keberfungsian keluarga. Keterlibatan afektif dapat diartikan sebagai sejauh mana anggota keluarga menunjukkan ketertarikan dan penghargaan kepada aktivitas dan minat anggota keluarga lainnya (Epstein et al., 1983). Hal ini tersebut terjadi karena budaya, tingkat pendidikan, jumlah keluarga dan keterampilan akan mempengaruhi ketelibatan keluarga terhadap anggota keluarga lainnya. Dalam penelitian Fleischmann, Haas, \& Fleischmann (2016) menjelaskan tingkat kelerlibatan keluarga tergantung pada tingkat pendidikan dan keterampilan keluarga.

Beberapa faktor lain yang juga berpengaruh terhadap penyesuaian sosial mahasiswa di perguruan tinggi seperti latar belakang keluarga, attachment dan komitmen. Pendapat tersebut sesuai dengan beberapa penelitian yang menunjukkan adanya pengaruh antara attachment dan latar belakang keluarga terhadap penyesuaian sosial mahasiswa seperti penelitian dari Paramo Fernandez, Araújo, Vacas, Almeida, \& González (2017) yang mengungkapkan bahwa prestasi pra-universitas dan latar belakang keluarga merupakan prediktor signifikan dari penyesuaian akademik dan sosial di universitas. Penelitian tersebut juga menjelaskan bahwa mahasiswa yang memiliki komitmen untuk menyelesaikan pendidikan mereka di perguruan tinggi berhubungan dengan penyesuaian sosial mereka di perguruan tinggi. Selanjutnya penelitian Akpan-idiok \& Ackley (2018) mengenai pengaruh latar belakang keluarga pada penyesuaian sosial siswa remaja di Nigeria menunjukkan bahwa remaja yang memiliki keluarga yang utuh lebih mudah melakukan penyesuaian sosial sedangkan remaja yang berasal dari keluarga yang tidak utuh atau broken home umumnya memiliki masalah perilaku dan penyesuaian sosial yang buruk.

Selain itu, penelitian Bray (1995) juga menunjukkan bahwa keutuhan orangtua 
berperan dalam mendorong anaknya untuk berkembang dan terus menunjukkan perilaku sosial yang dapat diterima secara etis yang sangat penting bagi penyesuaian sosial mereka di dalam dan di luar lingkungan rumah. Hal ini juga sejalan dengan penelitian Shek, Xie, \& Lin (2015) mengenai pengaruh struktur keluarga terhadap persepsi fungsi keluarga dalam konteks Cina pada remaja di Hong Kong yang menunjukkan bahwa keluarga utuh seperti orang tua yang utuh atau tidak bercerai dan meninggal memiliki lebih sedikit konflik dan fungsi keluarga serta komunikasi yang lebih baik daripada keluarga yang tidak utuh (orang tua yang bercerai atau meninggal). Hasil penelitian lain menyebutkan bahwa posisi dalam keluarga, jumlah anggota keluarga dan relasi dengan anggota keluarga lain akan mempengaruhi kebiasaan, sikap, dan pola perilaku individu (Sheehan \& larocci, 2015) serta distorsi kognitif remaja (Nasir et al., 2010). Hasil penelitian Rodgers \& Rose (2002) juga menyebutkan bahwa kurangnya kehangatan atau pengawasan orang tua dapat memicu munculnya perilaku anti sosial yang mencerminkan rendahnya penyesuaian sosial.

Penelitian yang meneliti tentang keberfungsian keluarga terhadap penyesuaian sosial pada mahasiswa baru ini merupakan penelitian yang baru di Indonesia. Hal tersebut menjadi kelebihan dari penelitian ini. Penelitian ini juga melibatkan jumlah subjek sebanyak 268 mahasiswa baru (mahasiswa angkatan 2018) di Universitas Muhammadiyah Malang. Keterbatasan dari penelitian ini adalah penelitian hanya dilaksanakan di Universitas Muhammadiyah Malang, sehingga hasil dari penelitiannya tidak dapat digeneralisasikan dengan daerah lain. Selain itu, penelitian ini juga tidak bisa memberikan hasil mengenai pengaruh data demografis subjek dikarenakan perbedaan jumlah responden berdasarkan gender, usia, status orang tua, tempat tinggal dan urutan anak yang sangat berbeda.

\section{Kesimpulan} Berdasarkan pada hasil penelitian
diperoleh bahwa hipotesa penelitian diterima yang berarti terdapat pengaruh positif keberfungsian keluarga terhadap penyesuaian sosial pada mahasiswa baru yang. Akan bermanfaat bagi mahasiswa baru jika mereka diberi informasi yang lebih realistis tentang apa yang akan terjadi di perguruan tinggi dan diajarkan keterampilan untuk mengembangkan penyesuaian sosial mereka saat baru memasuki lingkungan perguruan tinggi. Berbagai pihak seperti pihak kampus (staf dan dosen), teman-teman, dan keluarga harus memberikan dukungan agar mahasiswa dapat melakukan penyesuaian sosial di lingkungan perguruan tinggi. Rekomendasi untuk peneliti selanjutnya dapat menggunakan variabel lain untuk menjawab permasalahan yang berkaitan dengan penyesuaian sosial mahasiswa di perguruan tinggi seperti gender, budaya, sosial ekonomi, dll.

\section{Daftar Pustaka}

Akpan-idiok, P., \& Ackley, A. (2018). Influence of family background on social adjustment of adolescent students of southern senatorial district of cross river state, Nigeria. International Journal of Humanities Social Sciences and Education (IJHSSE), 5(8), 227-243.

Al-Ghamdi, B., \& Al-Nahal, M. (2014). Social adjustment and its relationship with the academic adjustment among a sample of gifted female students at Al-Baha Region. Al-Baha University.

Al-Rawwad, T. M. (2016). Parental Involvement and their Children' s Social Adjustment : Evidence from Jordanian Students. International Review of Social Sciences and Humanities, 11(2), 119-125.

Baker, R. W., \& Siryk, B. (1984). Measuring adjustment to College. Journal of Counseling Psychology, 31(2), 179189. https://doi.org/10.1037/00220167.31.2.179

Baker, R. W., \& Siryk, B. (1986). Exploratory intervention with a scale measuring adjustment to college. Journal of Counseling Psychology, 33(1), 31$38 . \quad$ https://doi.org/10.1037/00220167.33.1.31

Barbarin, O., \& Jean-Baptiste, E. (2013). 
The relation of dialogic, control, and racial socialization practices to early academic and social competence: Effects of gender, ethnicity, and family socioeconomic status. American Journal of Orthopsychiatry, 83(2 PART 3), 207217. https://doi.org/10.1111/ajop.12025

Bray, J. H. (1995). Family assessment: Current issues in evaluating families. Family Relation, 44(4), 469-477.

Byles, J., Byrne, C., Boyle, M. H., \& Offord, D. R. (1988). Ontario child health study: Reliability and validity of the general functioning subscale of the mcmaster family assessment device. Fam Proc, 27, 97-104.

Dai, L., \& Wang, L. (2015). Review of family functioning. Journal of Social Sciences, 3(December), 134-141. https://doi.org/http://dx.doi.org/10.4236/ jss.2015.312014 Review

Deepshikha, \& Bhanot, S. (2011). Role of family environment on socio-emotional adjustment of adolescent girls in rural areas of eastern uttar pradesh. $J$ Psychology, 2(1), 53-56.

Epstein-Lubow, G. P., Beevers, C. G., Bishop, D. S., \& Miller, I. W. (2009). Family functioning is associated with depressive symptoms in caregivers of acute stroke survivors. Archives of Physical Medicine and Rehabilitation, 90(6), 947-955. https://doi.org/10.1016/j. apmr.2008.12.014

Epstein, N. B., Baldwin, L. M., \& Bishop, D. S. (1983). The McMaster Family Assessment Device. Journal of Marital and Family Therapy, 9(2), 171-180.

Epstein, N. B., Bishop, D. S., \& Levin, S. (1978). The mcmaster model of family functioning. Journal of Marriage and Family Counseling, (October), 19-31.

Ernawati. (2011). Hubungan antara peran ibu, peran ayah dan kepercayaan diri dengan penyesuaian sosial remaja. Universitas Muhammadiyah Surakarta.

Estiane, U. (2015). Pengaruh dukungan sosial sahabat terhadap penyesuaian sosial mahasiswa baru di lingkungan perguruan tinggi. Jutnal Psikologi Klinis
Dan Kesehatan Mental, 04(1), 29-40.

Fleischmann, F., Haas, A. De, \& Fleischmann, F. F. (2016). Explaining parents' school involvement: The role of ethnicity and gender in the Netherlands. The Journal of Educational Research, 109(5), 554565. https://doi.org/10.1080/00220671. 2014.994196

Hughes, D. J. (2018). Psychometric validity: Establishing the accuracy and appropriateness of psychometric measures. In The Wiley Handbook of Psychometric Testing: A Multidisciplinary Reference on Survey, Scale and Test Development (First Edit, pp. 751-774). Hoboken: Wiley.

Hurlock, E. B. (2003). Perkembangan suatu pendekatan sepanjang rentang kehidupan (Kelima). Jakarta: Erlangga.

Julia, M., \& Veni, B. (2012). An Analysis of the Factors Affecting Students ' Adjustment at a University in Zimbabwe, 5(6), 244-250. https://doi.org/10.5539/ies. v5n6p244

Kaljahi, N. E. (2016). The effects of academic adjustment, social adjustment and personal-emotional adjustment of students on their academic performance in universities of northern cyprus. Eastern Mediterranean University. Retrieved from http://i-rep.emu.edu. tr:8080/jspui/bitstream/11129/2927/1/ kaljahiniusha.pdf

Magnuson, K., Duncan, G. J., Lee, K. T. H., \& Metzger, M. W. (2016). Early school adjustment and educational attainment. American Educational Research Journal, 53(4), 1198-1228. https://doi. org/10.3102/0002831216634658

Maundeni, T., Malinga, T., Kgwatalala, D., \& Kasule, I. (2010). Cultural adjustment of international students at an african university. Journal of Psychology in Africa, 20(1), 37-41. https://doi.org/10. 1080/14330237.2010.10820345

Mistry, R. S., Vandewater, E. A., Huston, A. C., \& Mcloyd, V. C. (2018). Economic wellbeing and children's social adjustment : The role of family process in an ethnically diverse low-income sample. Society for 
Research in Child Development, 73(3), 935-951.

Mohammadyfar, M. A., Kazemi, S., \& Matekolaee, E. Z. (2016). The role of students' family function and selfefficacy in social adjustment. Journal of School Psychology, 5(4), 117-132.

Najam us Sahar, \& Muzaffar, N. (2017). Role of family system , positive emotions and resilience in social adjustment among pakistani adolescents. Journal of Educational, Health and Community Psychology, 6(2), 46-58.

Nasir, R., Ahmad, Z., Khairudin, R., \& Latipun. (2010). Effects of family functioning , self-esteem, and cognitive distortion on depression among malay and indonesian juvenile delinquents. Procedia Social and Behavioral Sciences, 7(C), 613-620. https://doi. org/10.1016/j.sbspro.2010.10.083

Panourgia, C., \& Comeretto, A. (2017). Do cognitive distortions explain the longitudinal relationship between life adversity and emotional and behavioural problems in secondary school children ? Stress and Health, (March), 1-10. https://doi.org/10.1002/smi.2743

Paramo Fernandez, M. F., Araújo, A. M., Vacas, C. T., Almeida, L. S., \& González, M. S. R. (2017). Predictors of students' adjustment during transition to university in spain. Psicothema, 29(1), 67-72. https://doi.org/10.7334/ psicothema2016.40

Parsian, M., Igoli, S. K., \& Sayadi, S. (2017). The effect of family function on social adjustment and self- regulation of high school students. International Journal of Social Sciences and Humanities Research, 5(4), 21-28.

Rahayu, P. P., \& Hartati, S. (2015). Dukungan sosial ayah dengan penyesuaian sosial pada remaja laki-laki. Jurnal Empati, 4(4), 334-339.

Rhoades, G. K., \& Wood, L. F. (2014). Family conflict and college-student social adjustment: The mediating role of emotional distress about the family. Couple and Family Psychology:
Research and Practice, 3(3), 156-164. https://doi.org/10.1037/cfp0000024

Roberson, P. N. E., Fish, J. N., Olmstead, S. B., \& Fincham, F. D. (2015). College adjustment, relationship satisfaction, and conflict management: A cross-lag assessment of developmental "spillover." Emerging Adulthood, 3(4), 1-11. https:// doi.org/10.1177/2167696815570710

Rodgers, K. B., \& Rose, H. A. (2002). Risk and resiliency factors among adolescents who experience marital transitions. Journal of Marriage and Family, 64(November), 1024-1037.

Santrock, J. W. (2007). Remaja (11th ed.). Jakarta: Erlangga.

Schneider, M. E., \& Ward, D. J. (2003). The role of ethnic identification and perceived social support in latinos' adjustment to college. Hispanic Journal of Behavioral Sciences, 25(4), 539-554. https://doi. org/10.1177/0739986303259306

Schneiders, A. A. (2010). Personal adjustment and mental health. New York: Holt, Rinehart and Winston. https://doi. org/10.1038/nature11321

Sheehan, W. A., \& larocci, G. (2015). Executive functioning predicts academic but not social adjustment to university. Journal of Attention Disorders, 1-9. https://doi. org/10.1177/1087054715612258

Shek, D. T. L. (1997). The relation of family functioning to adolescent psychological well-being, school adjustment, and problem behavior. Journal of Genetic Psychology, 158(4), 467-479. https:// doi.org/10.1080/00221329709596683

Shek, D. T. L. (2002). Family functioning and psychological well-being, school adjustment, and problem behavior in chinese adolescents with and without economic disadvantage. American Journal of Family Therapy, 30(3), 215-230. https://doi. org/10.1080/019261802753577548

Shek, D. T. L., Xie, Q., \& Lin, L. (2015). The impact of family intactness on family functioning, parental control, and parent - child relational qualities in a Chinese context, 2(January), 1-7. https://doi. 
org/10.3389/fped.2014.00149

Smojver-Azic, S., Zivcic-Becirevic, I., \& Jakov, I. (2010). The contribution of personality traits and academic and social adjustment to life satisfaction and depression in college freshmen. Horizons of Psychology, 19(3), 5-18.

Soledad, R. G. M., Carolina, T. V., Adelina, G. C. M., \& Páramo Fernández, M. F. (2012). The student adaptation to college questionnaire (sacq) for use with spanish students. Psychological Reports Measures \& Statistics, 111(2), 624640. https://doi.org/10.2466/08.10.20. PR0.111.5.624-640

Syaripudin, O., \& Djamhoer, T. D. (2017). Hubungan antara kontrol diri dengan penyesuaian sosial di pesantren pada santri pondok pesantren al-falah Bandung. Prosiding Psikologi, 3(1), 123-128.

Usoroh, C. I., Akpan, I. D., Amadi, N. B., \& Ezenwa, H. C. (2014). A comparative study of the effect of family types on social adjustment of adolescent in aba, abia state. Civil and Environmental Research, 6(8), 6-11.

Willis, S. S. (2012). Remaja dan masalahnya. Bandung: CV. Alfabeta.

Winarsunu, T. (2017). Statistik dalam penelitian psikologi dan pendidikan (7th ed.). Malang: UMM Press.

Yusoff, Y. M., \& Chelliah, S. (2010). Adjustment in international students in malaysian public university. International Journal of Innovation, Management and Technology, 1(3), 275-278. 